\title{
Comparison of the Acidity of Heteropolyacids Encapsulated in or Impregnated on SBA-15
}

\author{
Teresa Pinto ${ }^{1}$, Kai Szeto ${ }^{1}$, Nesrine Oueslati ${ }^{1}$, Nadine Essayem$^{2}$, Véronique Dufaud ${ }^{1 *}$ \\ and Frédéric Lefebvre ${ }^{1 *}$ \\ ${ }^{1}$ Laboratory of Chemistry, Catalysis, Polymers and Processes (C2P2), University of Lyon 1, CNRS, CPE, UMR 5265, \\ 43 Bd du 11 Novembre 1918, 69616 Villeurbanne - France \\ 2 Institut de Recherches sur la Catalyse et l'Environnement de Lyon (IRCELyon), University of Lyon 1, CNRS, UMR 5256, \\ 2 Avenue Albert Einstein, 69626 Villeurbanne - France \\ e-mail: teresapspinto@gmail.com - kai-chung.szeto@univ-lyon 1.fr - nesrine.oueslati@cpe.fr \\ nadine.essayem@ircelyon.univ-lyon 1.fr - veronique.dufaud@univ-lyon 1.fr - frederic.lefebvre@univ-lyon 1.fr \\ * Corresponding authors
}

\begin{abstract}
Heteropolyacids (HPA) immobilized onto SBA-15 silica were prepared by two different ways using either impregnation or encapsulation methodologies. Two Keggin-type $\mathrm{HPA}, \mathrm{H}_{3} \mathrm{PW}_{12} \mathrm{O}_{40}$ and $\mathrm{H}_{4} \mathrm{Si}_{12} \mathrm{O}_{40}$ were considered in this study. The resulting hybrid materials were fully characterized by $\mathrm{N}_{2}$ adsorption-desorption isotherms, XRD, FT-IR, Raman, diffuse reflectance UV-Vis spectroscopies and ${ }^{31} P$ MAS NMR. All characterization methods showed that at room temperature the catalysts contained well-dispersed and intact Keggin units throughout the solid. The catalytic activity of these solids was investigated in the isomerization of n-hexane. The impregnated and encapsulated phosphotungstic catalysts performed similarly in catalysis showing that the amount of active sites was nearly the same in both catalysts. On the contrary, the tungstosilicic encapsulated material was completely inactive while its impregnated counterpart was even more active than the phosphotungstic derived catalysts. The acidity of the solids was measured by various methods: microcalorimetry of ammonia adsorption, ammonia desorption followed by Temperature Programmed Desorption (TPD) and DRIFT/GC-MS and pyridine adsorption followed by infrared spectroscopy. Only pyridine adsorption and ammonia desorption followed by DRIFT/GC-MS agreed with the catalytic data. Ammonia adsorption followed by microcalorimetry was not able to differentiate between the four catalysts while the TPD experiments led to unreliable results, as not only the evolved ammonia but also other molecules such as water were taken into account in the measurements. The behavior difference between the encapsulated silico- and phosphotungstic acids was explained by a more pronounced encapsulation in the case of silicon.
\end{abstract}

Résumé - Comparaison des propriétés acides d'hétéropolyacides encapsulés ou imprégnés dans une matrice de type SBA-15 - Deux types de catalyseurs à base d'hétéropolyacides (HPA) immobilisés sur une silice de type SBA-15 ont été préparés en utilisant soit une méthode par imprégnation soit une méthode par encapsulation. Deux hétéropolyacides à structure de Keggin ont été étudiés, $\mathrm{H}_{3} \mathrm{PW}_{12} \mathrm{O}_{40}$ et $\mathrm{H}_{4} \mathrm{SiW}_{12} \mathrm{O}_{40}$. Les solides ainsi obtenus ont été totalement caractérisés par diverses techniques physico-chimiques (isothermes d'adsorption-désorption d'azote, diffraction des Rayons X, spectroscopies infrarouge et Raman, spectroscopie UV-visible par réflectance et RMN du solide du phosphore-31). Toutes les techniques de caractérisation indiquent qu'à température ambiante les hétéropolyacides ont conservé leur structure de Keggin et ce quelle que soit la méthode 
de préparation. L'activité catalytique de ces matériaux a ensuite été étudiée dans l'isomérisation du $n$-hexane. Les systèmes formés à partir de $\mathrm{H}_{3} \mathrm{PW}_{12} \mathrm{O}_{40}$ ont un comportement similaire indépendant de la méthode de préparation, en accord avec un nombre de sites actifs quasiment identique. Par contre, dans le cas de $\mathrm{H}_{4} \mathrm{SiW}_{12} \mathrm{O}_{40}$, le catalyseur préparé par encapsulation est inactif alors que celui préparé par imprégnation présente une activité comparable aux systèmes phosphotungstiques précédents. L'acidité des solides a été mesurée par diverses méthodes : microcalorimétrie d'adsorption d'ammoniac, thermodésorption d'ammoniac suivie par TPD et spectroscopie infrarouge couplée à un système GC-MS (DRIFT/GC-MS) et adsorption de pyridine suivie par spectroscopie infrarouge. Seules l'adsorption de pyridine et les mesures de désorption d'ammoniac suivie par DRIFT donnent des résultats concordants avec les résultats de catalyse. La microcalorimétrie a donné des résultats comparables pour les quatre systèmes tandis que la désorption d'ammoniac suivie par TPD ne conduit pas à des résultats interprétables, les valeurs obtenues prenant en compte non seulement l'ammoniac désorbée mais aussi d'autres molécules, notamment de l'eau. La différence entre les deux matériaux encapsulés a été interprétée comme provenant d'une encapsulation plus prononcée de l'hétéropolyacide dans le cas de $\mathrm{H}_{4} \mathrm{SiW}_{12} \mathrm{O}_{40}$.

\section{INTRODUCTION}

Heteropolyoxometalates (POM) have been widely applied in homogeneous or heterogeneous catalysis due to their unique physico-chemical, acid-base and redox properties [1]. Different types of polyoxometalates exist, such as the Keggin $\mathrm{H}_{n} \mathrm{XM}_{12} \mathrm{O}_{40}$ or the Dawson $\mathrm{H}_{n} \mathrm{X}_{2} \mathrm{M}_{18} \mathrm{O}_{62}$ structures. However, the Keggin compounds have been extensively studied as they are the most stable and acidic when the cation of compensation is the proton. Their very strong Brønsted acidity allows them to be potentially good candidates for acid catalysis. Unfortunately, their low specific surface area in the solid state $\left(1-10 \mathrm{~m}^{2} / \mathrm{g}\right)$ and their high solubility in polar solvents are obstacles to their development in heterogeneous catalysis [2-4]. These problems can be overcome by two ways: either by immobilizing them onto high surface area supports to improve the dispersion of the active phase or through the direct synthesis of acidic porous salts. The immobilization onto oxide supports, such as silica, zirconia or $\gamma$-alumina, can also induce some changes in the redox properties and acid strength or, in some cases, may lead to some decomposition of the HPA $[5,6]$. The best support seems to be silica as it does not modify strongly the properties of the polyacid. Among all types of silica, mesoporous silicas are good candidates as supports as they have very high surface areas (up to $1000 \mathrm{~m}^{2} \cdot \mathrm{g}^{-1}$ ) with large and uniform pore sizes ( $\sim 6 \mathrm{~nm}$ diameter for SBA-15). These characteristics provide ample room for reactant and product diffusion, and the thick walls offer greater hydrothermal and mechanical stability [7-9]. The most known routes to successfully prepare HPA supported onto SBA-15 (or MCM-41) are the classical impregnation method and the direct synthesis. These methods, when optimized, can yield hybrid materials with structured and large pore sizes, showing a stable and uniform distribution of the active phase over the solid and intact Keggin structures [10].

Over the last decades, HPA have been used in numerous acid-catalyzed reactions requiring highly acidic sites such as the skeletal isomerization of $n$-alkanes [11-15]. This reaction is becoming an important way to produce clean fuels, as it satisfies most of the environmental specification requirements for fuel production as well as provides an efficient way to increase the octane number of motor gasoline [16].

Currently, bifunctional catalysts are used in the industrial isomerization processes [17]. One function is an acid catalyst while the other is a hydrogenation-dehydrogenation catalytic system (typically a noble metal). Typical examples are based on platinum catalysts supported either on chlorinated alumina [18] or zeolites such as mordenite [19]. The latter catalysts are particularly advantageous as they are less corrosive and less prone to deactivation by the contaminants (i.e. water, sulfur) present in the feed [20, 21]. Nevertheless, Pt-zeolites catalysts present some disadvantages such as high operating temperatures, high hydrogen pressure and lower acidity which, in the end, leads to lower selectivity to branched molecules [22-24]. As a consequence, the development of new solid acid catalysts with higher acid strength is highly required for such isomerization reactions.

In a previous paper, we have reported on the use of $\mathrm{H}_{3} \mathrm{PW}_{12} \mathrm{O}_{40}$ (HPW) and $\mathrm{H}_{4} \mathrm{SiW}_{12} \mathrm{O}_{40}$ (HSiW) supported on SBA-15 for the isomerization of $n$-hexane in the gas phase [25]. These catalysts were prepared by using classical impregnation methodologies. The best results were obtained with the silicotungstic acid but all systems were found to be active and highly selective towards branched isomers even though deactivation by coke formation occurred with time on stream. 
In the present report, we wish to investigate an alternative method to HPA containing SBA-15 materials, developed recently by us, where the HPA entities are not held at the silica surface but directly encapsulated within the silica framework, and compare their performance with that of conventionally impregnated materials in the isomerization of $n$-hexane. Both types of catalysts were thoroughly characterized using different analytical and spectroscopic techniques to allow for the establishment of structure-activity relationships. In particular, the acidity of the resulting hybrid materials was examined in details using three classical methods of heterogeneous catalysis, namely TPD of adsorbed ammonia, microcalorimetry of ammonia adsorption and pyridine adsorption. We shall see that only pyridine adsorption and ammonia desorption followed by DRIFT/GC-MS measurements agreed in a meaningful manner with catalytic results, ammonia adsorption followed by microcalorimetry being not able to differentiate between the four catalysts.

\section{EXPERIMENTAL}

\subsection{Synthesis of the Catalysts}

The supported HPA were prepared by conventional impregnation (noted HPA/SBA-15 in the following), or sol-gel encapsulation method (noted HPA@SBA-15). The $\mathrm{H}_{3} \mathrm{PW}_{12} \mathrm{O}_{40}$ and $\mathrm{H}_{4} \mathrm{SiW}_{12} \mathrm{O}_{40}$ HPA were purchased from Aldrich and used as received. SBA-15 was prepared according to literature procedures [9]. The HPA/SBA-15 catalysts were prepared in methanol as described previously [25] and were dried at $80^{\circ} \mathrm{C}$ in an oven. The HPA@SBA-15 materials were prepared according to the procedure described previously for encapsulated $\mathrm{H}_{3} \mathrm{PW}_{12} \mathrm{O}_{40}$ [26]. The samples were calcined in air saturated with water from room temperature until $220^{\circ} \mathrm{C}$ for $6 \mathrm{~h}$ and then heated up to $400^{\circ} \mathrm{C}$ for $20 \mathrm{~h}$. All solids contained around $33 \mathrm{wt} \%$ of HPA.

\subsection{Physical Characterization of the Catalysts}

Transmission FT-IR spectra were recorded on a Nicolet 5700 spectrometer in the $400-4000 \mathrm{~cm}^{-1}$ range from $\mathrm{KBr}$ pellets (resolution $4 \mathrm{~cm}^{-1}, 32$ scans). The ${ }^{31} \mathrm{P}$ MAS NMR spectra were recorded on a Bruker Avance-500 spectrometer, operating at $202.40 \mathrm{MHz}$ with a classical $4 \mathrm{~mm}$ probe-head allowing spinning rates up to $10 \mathrm{kHz}$ (recycle delay $15 \mathrm{~s}$, 3000 scans). The X-ray diffraction patterns of samples were recorded on a Bruker D5005 diffractometer by using the $\mathrm{Cu}$ $\mathrm{K} \alpha_{1}$ monochromatic radiation $(\lambda=1.54184 \AA)$. $\mathrm{N}_{2}$ adsorption-desorption was performed on a Micromeritics ASAP 2020 system. The samples were evacuated at $350^{\circ} \mathrm{C}$ for $12 \mathrm{~h}$ before the experiment. The surface area and the $C$ constant were obtained from the BET equation and the pore size distribution was calculated by the $\mathrm{BJH}$ method applied to the desorption branch of the nitrogen adsorption/desorption isotherm. Elemental analyses were performed by ICP-AES with a ICP spectroflamme-D from a solution obtained by treatment of the solid catalysts with a mixture of $\mathrm{HF}, \mathrm{HNO}_{3}$ and $\mathrm{H}_{2} \mathrm{SO}_{4}$ in a Teflon reactor at $150^{\circ} \mathrm{C}$. Diffuse reflectance UV-Visible spectra were acquired using a Perkin Elmer Lambda 1050 UV/VIS/NIR spectrometer equipped with a praying Mantis equipment (Harrick ${ }^{T M}$ ) for solid analysis. The acquisition domain was $200-800 \mathrm{~nm}$ with an acquisition step of $2 \mathrm{~nm}$. Raman studies were made on a DXR Raman Microscope (Thermo Scientific) spectrometer equipped with an automated confocal microscope, SmartLock filters and a Charge-Coupled Device (CCD) detector. The excitation was provided at $780 \mathrm{~nm}$ and focused with a $50 \times$ long working distance objective. The spectra were obtained with a maximum power of $7 \mathrm{~mW}$ on the sample and a $5 \mathrm{~cm}^{-1}$ resolution. The TGA/DTA analysis was performed on a Mettler Toledo TGA DSC 1 apparatus. The samples were heated under air from $25^{\circ} \mathrm{C}$ to $1000^{\circ} \mathrm{C}$ at a rate of $10^{\circ} \mathrm{C} \cdot \mathrm{min}^{-1}$.

\subsection{Measurement of Catalysts Acidity}

The acidity of the catalysts was studied by microcalorimetry of ammonia adsorption, TPD of ammonia desorption and infrared study of pyridine adsorption. For the calorimetry experiments, the study was carried out on a Tian-Calvet calorimeter coupled to volumetric equipment. The samples $\left(\sim 50 \mathrm{mg}\right.$ ) were first pretreated at $200^{\circ} \mathrm{C}$ for $1 \mathrm{~h}$ under secondary vacuum $\left(10^{-5}\right.$ Torr). Then, the solid was cooled and submitted at $80^{\circ} \mathrm{C}$ to successive small doses of gas up to equilibrium. The differential enthalpy of each adsorption was recorded together with the amount of $\mathrm{NH}_{3}$ adsorbed.

For the $\mathrm{NH}_{3}$-TPD experiments, the solids were first treated under helium $(P=1 \mathrm{bar})$ at $300^{\circ} \mathrm{C}$ for $1 \mathrm{~h}$. After cooling the sample to $100^{\circ} \mathrm{C}$, a permutation of helium to a gas mixture of $15 \% \mathrm{NH}_{3}$ in argon was passed through it during 30 minutes. Ammonia was then desorbed upon heating at $750^{\circ} \mathrm{C}$ under helium while the evolved gases were analyzed by TCD.

Desorption of ammonia was also monitored by combined DRIFT and GC-MS. The experiments were carried out in an integrated system comprising mass flow controllers (Brooks), high temperature reaction chamber (Harrick ${ }^{T M}$ ) with ZnSe windows, a Nicolet FT-IR 6700 spectrophotometer equipped with MCT detector and online GC-MS (Agilent $6850 / 5975 C)$. The sample was individually placed on the high temperature reaction chamber in an Ar-filled glove box. This cell was fitted into a Praying Mantis optical unit (Harrick $^{T M}$ ) and connected to the gas lines. The samples were first treated under vacuum $\left(P=10^{-5}\right.$ Torr $)$ at $275^{\circ} \mathrm{C}$ 
for $20 \mathrm{~h}$ and then exposed to ammonia ( $\geq 99.95 \%$, GHC Gerling Holz + Co.) in excess at room temperature. During the FT-IR acquisition, $5 \mathrm{~mL} \cdot \mathrm{min}^{-1}$ of purified (molecular sieve/deoxo catalyst) argon (99.999\%, Air Liquide) was constantly flowing through the sample which was heated from 20 to $400^{\circ} \mathrm{C}$ at $2^{\circ} \mathrm{C} . \mathrm{min}^{-1}$. Each spectrum was acquired by 64 scans with a resolution of $4 \mathrm{~cm}^{-1}$. The output gas was separated with a $25 \mathrm{~m}$ PoraBOND Q column and analyzed by mass spectrometer in SIM mode $(\mathrm{m} / \mathrm{z}=15-17)$.

The adsorption of pyridine was studied on a Nicolet 5700 FT-IR spectrometer equipped with a $\mathrm{KBr}$ beam splitter and a DTGS detector, allowing recording the spectra of the solids in situ. The FT-IR spectra were recorded at a $4 \mathrm{~cm}^{-1}$ resolution. The catalyst samples were first pressed in a selfsupporting pellet. They were then activated overnight at $200^{\circ} \mathrm{C}$ under vacuum at $10^{-5}$ Torr, in a quartz IR cell equipped with $\mathrm{CaF}_{2}$ windows. Pyridine adsorption was carried out by equilibrating the catalyst pellet for $10 \mathrm{~min}$ with a large amount of base at room temperature, and then the spectrum was recorded. The desorption of the pyridine was successively monitored by evacuating the sample for 1 hour at each temperature (room temperature, 50, 100, 150 and $200^{\circ} \mathrm{C}$ ). The samples were cooled to room temperature between each step and the FT-IR spectrum was recorded.

\subsection{Catalytic Experiments}

Isomerization of $n$-hexane was carried out in a fixed bed dynamic flow reactor at atmospheric pressure. The catalyst was weighted and charged into a stainless steel $1 / 2$ ' cylindrical reactor. The reactor was then placed in an oven. Before allowing the $n$-hexane feed to pass through the reactor, the catalyst was activated to remove the remaining water molecules. This was made by treatment under argon (flow rate $5 \mathrm{~mL} \cdot \mathrm{min}^{-1}$ ) during $2 \mathrm{~h}$ at $200^{\circ} \mathrm{C}$. After activation of the catalyst, the reaction mixture $\left(5 \mathrm{~mL} \cdot \mathrm{min}^{-1}\right.$ of argon flow in contact with liquid hexane ( $>99 \%$ provided by SigmaAldrich), at $25^{\circ} \mathrm{C}$, partial pressure of $n$-hexane $=151$ Torr, ratio hexane/argon $=0.25$ ) was allowed to pass through the reactor at the desired temperature. The experiment was conducted during $12 \mathrm{~h}$. The reaction products (hexane isomers and cracking products) were analyzed online by Gas Chromatography (GC) equipped with a Flame Ionization Detector (FID) and a non-polar capillary $\mathrm{KCl} / \mathrm{Al}_{2} \mathrm{O}_{3}$ column (Varian capillary column; $50 \mathrm{~m} \times 530 \mu \mathrm{m} \times 15 \mu \mathrm{m}$ ). The conversion was calculated from the surface of the peak of $n$-hexane before and after reaction. The selectivities were calculated from the peaks of the corresponding products. Selectivity towards isomerization was defined as the amount of isomerization products (excluding $n$-hexane) versus the total amount of products.

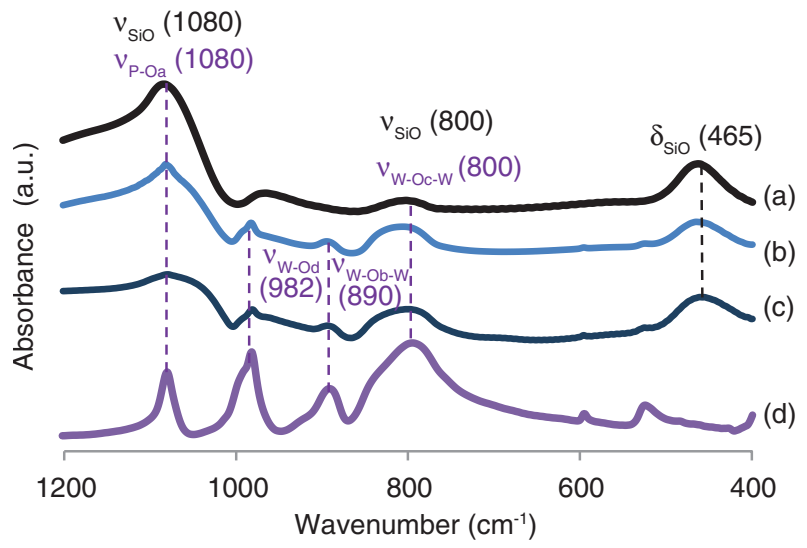

Figure 1

FT-IR spectra of supported HPW catalysts: a) pure SBA-15; b) HPW/SBA-15; c) HPW@SBA-15 and d) pure HPW.

\section{RESULTS AND DISCUSSION}

\subsection{Structural State of the HPA in the Catalysts}

Various molecular characterization techniques were used in order to determine if the Keggin structure had been preserved after the preparation of the catalysts: DR UV-Vis, Raman and FT-IR spectroscopies and ${ }^{31}$ P MAS NMR.

The FT-IR of all hybrid materials are shown in Figure 1 (for the HPW family) and Figure 2 (for the HSiW family), together with those of the bulk HPA and SBA-15. The spectra of phosphotungstic acid derived catalysts, HPW@SBA-15 and HPW/SBA-15, clearly showed the characteristic bands of the $\left[\mathrm{PW}_{12} \mathrm{O}_{40}\right]^{3-}$ Keggin anion at $1080\left(v_{\mathrm{as}}\left(\mathrm{P}-\mathrm{O}_{\mathrm{a}}\right)\right), 982\left(\mathrm{v}_{\mathrm{as}}\left(\mathrm{W}-\mathrm{O}_{\mathrm{d}}\right)\right), 890\left(\mathrm{v}_{\mathrm{as}}\left(\mathrm{W}-\mathrm{O}_{\mathrm{b}}-\mathrm{W}\right)\right)$, and $800 \mathrm{~cm}^{-1}\left(v_{\mathrm{as}}\left(\mathrm{W}-\mathrm{O}_{\mathrm{c}}-\mathrm{W}\right)\right)$ [9]. Similarly, the FTIR spectra of the HSiW@SBA-15 and HSiW/SBA-15 materials displayed bands at $978\left(v_{\mathrm{as}}\left(\mathrm{W}-\mathrm{O}_{\mathrm{d}}\right)\right), 928\left(\mathrm{v}_{\mathrm{as}}\left(\mathrm{Si}-\mathrm{O}_{\mathrm{a}}\right)\right), 876$ $\left(v_{a s}\left(\mathrm{~W}-\mathrm{O}_{\mathrm{b}}-\mathrm{W}\right)\right)$, and $775 \mathrm{~cm}^{-1}\left(\mathrm{v}_{\mathrm{as}}\left(\mathrm{W}-\mathrm{O}_{\mathrm{c}}-\mathrm{W}\right)\right)$ [9] suggesting that at least part of the Keggin structures was preserved during the preparation of the samples whether they were impregnated over the support or encapsulated during solgel synthesis.

The HPW@SBA-15 and HPW/SBA-15 catalysts were also characterized by ${ }^{31} \mathrm{P}$ MAS NMR. The spectra confirmed that the Keggin structure had been retained in the two cases, as they showed a sharp peak at -15 ppm (Supporting Information, Fig. S1) which could be attributed to the hydrated $\left[\mathrm{PW}_{12} \mathrm{O}_{40}\right]^{3-}$ anion [9]. A small peak at -12 ppm was also observed in the case of the encapsulated material and attributed to the presence of dehydrated polyanion [27, 28]. 


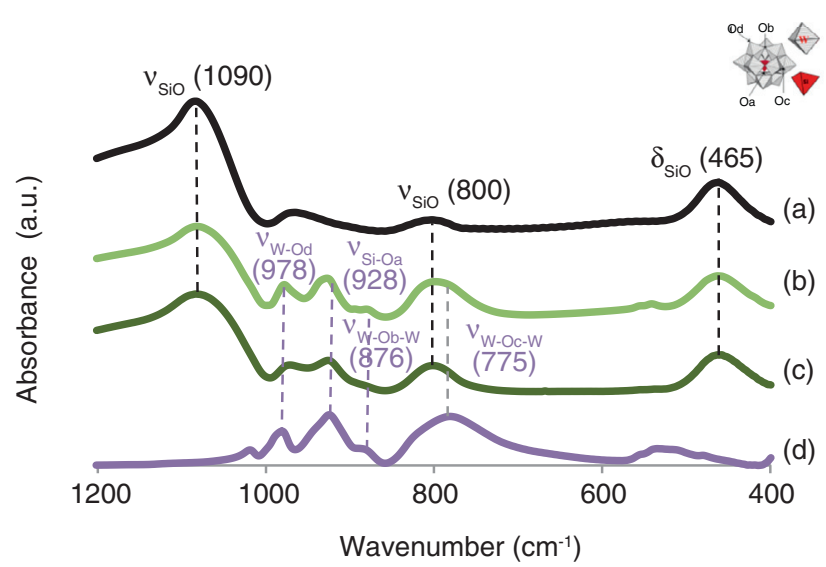

Figure 2

FT-IR spectra of supported HSiW catalysts: a) pure SBA-15; b) HSiW/SBA-15; c) HSiW@SBA-15 and d) pure HSiW.

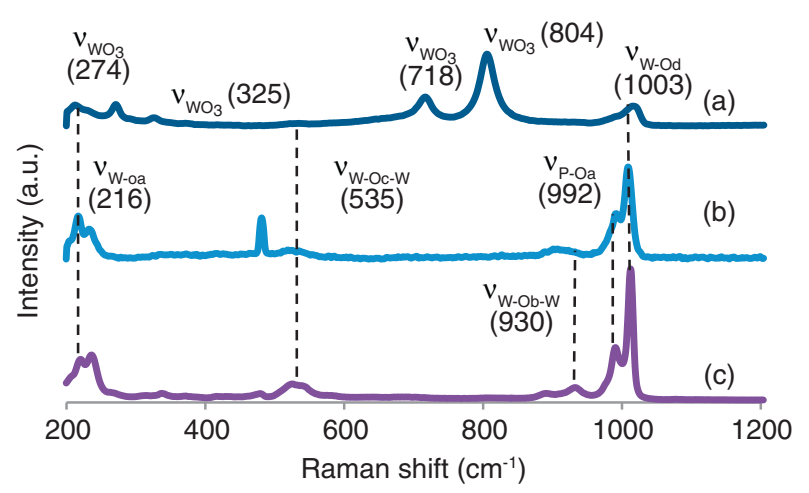

Figure 3

Raman spectra of the HPW catalysts: a) HPW@SBA-15; b) HPW/SBA-15 and c) pure HPW.

The Raman spectra of the four catalysts and of the pure HPA are shown in Figures 3 and 4. Clearly, there is a considerable difference between the spectra of the impregnated and encapsulated polyacids. The solids prepared by impregnation led to spectra quite similar to those of the pure HPA with bands at $1003\left(v_{\mathrm{s}}\left(\mathrm{W}=\mathrm{O}_{\mathrm{d}}\right)\right)$, 995-980 $\left(\mathrm{v}_{\mathrm{s}}\left(\mathrm{P}-\mathrm{O}_{\mathrm{a}}\right), \mathrm{v}_{\mathrm{as}}\left(\mathrm{W}=\mathrm{O}_{\mathrm{d}}\right)\right)$, $930\left(v_{\mathrm{as}}\left(\mathrm{W}-\mathrm{O}_{\mathrm{b}}-\mathrm{W}\right)\right), 535\left(\mathrm{v}_{\mathrm{s}}\left(\mathrm{W}-\mathrm{O}_{\mathrm{c}}-\mathrm{W}\right)\right)$ and $216 \mathrm{~cm}^{-1}$ $\left(v_{s}\left(W-O_{a}\right)\right)[29,30]$ in the case of phosphorus-based materials and bands at $1000 \quad\left(v_{\mathrm{s}}\left(\mathrm{W}=\mathrm{O}_{\mathrm{d}}\right)\right), 928 \quad\left(\mathrm{v}\left(\mathrm{Si}-\mathrm{O}_{\mathrm{a}}\right)\right)$, $540\left(v_{\mathrm{s}}\left(\mathrm{W}-\mathrm{O}_{\mathrm{c}}-\mathrm{W}\right)\right)$, and $221 \mathrm{~cm}^{-1}\left(\mathrm{v}\left(\mathrm{W}-\mathrm{O}_{\mathrm{a}}\right)\right)[30,31]$ for the silicotungstic derivatives.

The Raman spectra of the two encapsulated catalysts are quite comparable and showed mainly two bands at 807 and $718 \mathrm{~cm}^{-1}$ and small bands at ca. 325 and $274 \mathrm{~cm}^{-1}$. All these bands can be attributed to tungsten trioxide $\mathrm{WO}_{3}$ $[29,32]$. In the case of the HPW@SBA-15 catalyst, the

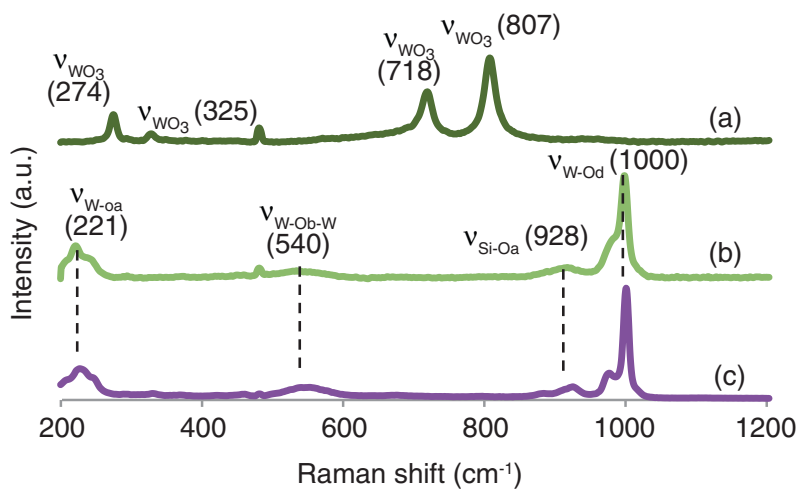

Figure 4

Raman spectra of the HSiW catalysts: a) HSiW@SBA-15; b) $\mathrm{HSiW} / \mathrm{SBA}-15$ and c) pure HSiW.

bands of the HPA at ca. $1000 \mathrm{~cm}^{-1}\left(v_{\mathrm{s}}\left(\mathrm{W}=\mathrm{O}_{\mathrm{d}}\right)\right)$ can also be seen but they are broadened and of low intensity. These results indicate that there is a partial (in the case of HPW@SBA-15) or complete (in the case of HSiW@SBA15) degradation of the polyoxometalate ions which contradicts the FT-IR data for HSiW@SBA-15. One plausible explanation would be that, in the case of the encapsulated materials, the polyoxometalate species have been decomposed under the laser beam. We tried to decrease the power of the laser beam in order to eliminate this effect but due to a high fluorescence of the samples it was not possible to decrease it below $3 \mathrm{~mW}$. As the main effect of the laser beam is to heat locally the sample, this suggests that the encapsulated materials are thermally less stable than the impregnated ones, leading to the following order of thermal stability:

$$
\begin{gathered}
\text { HSiW@SBA-15 < HPW@SBA-15 < } \\
\text { HSiW } / \text { SBA-15 } \approx \text { HPW } / \text { SBA-15 }
\end{gathered}
$$

A study by Differential Thermal Analysis (DTA) confirmed this conclusion (Fig. S2 and S3) even though the exothermic peaks associated with the decomposition of the polyoxometalates (or the crystallization of the simple oxides resulting from this decomposition) were not very intense. Decomposition temperatures, determined by the inflexion point of the curves, were found at ca.:

- $580^{\circ} \mathrm{C}$ for HPW/SBA-15,

- 520 ${ }^{\circ} \mathrm{C}$ for HPW@SBA-15,

- $530^{\circ} \mathrm{C}$ for HSiW/SBA-15,

- 390 ${ }^{\circ} \mathrm{C}$ for HSiW@SBA-15.

These values can be only approximated due to the small variations of the curves but they are in quite good agreement with those deduced from the Raman study, the encapsulated materials being less stable than those obtained by impregnation. 
TABLE 1

Textural and physical properties of HPW and HSiW hybrid materials

\begin{tabular}{|c|c|c|c|c|c|c|c|c|c|}
\hline Catalysts & $\mathrm{wt} \% \mathrm{~W}$ & $\begin{array}{c}d_{100}^{\left({ }^{a}\right)} \\
(\AA))\end{array}$ & $\begin{array}{l}a_{0}{ }^{(b)} \\
(\AA)\end{array}$ & $\begin{array}{c}S_{B E T} \\
\left(\mathrm{~m}^{2} / \mathrm{g}\right)\end{array}$ & $\begin{array}{c}\text { Wall thickness } \\
(\AA)\end{array}$ & $\begin{array}{c}V_{p}{ }^{(\mathrm{d})} \\
\left(\mathrm{cm}^{3} / \mathrm{g}\right)\end{array}$ & $\begin{array}{c}V_{\mu}{ }^{\left({ }^{\circ}\right)} \\
\left(\mathrm{cm}^{3} / \mathrm{g}\right)\end{array}$ & 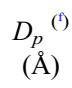 & $C_{B E T}^{\left({ }^{(g)}\right.}$ \\
\hline SBA-15 & - & 98 & 113 & 834 & 37 & 1.10 & 0.05 & 76 & 161 \\
\hline HPW/SBA-15 & 24.6 & 97 & 112 & 452 & 34 & 0.60 & 0.04 & 77 & 241 \\
\hline HPW@SBA-15 & 27.7 & 95 & 109 & 368 & 34 & 0.48 & 0.04 & 75 & 333 \\
\hline HSiW/SBA-15 & 24.7 & 97 & 112 & 503 & 35 & 0.65 & 0.04 & 77 & 266 \\
\hline HSiW@SBA-15 & 22.6 & 101 & 116 & 392 & 41 & 0.70 & 0.02 & 75 & 138 \\
\hline
\end{tabular}

a $d(100)$ spacing (estimated error $3 \AA$ ).

${ }^{\mathrm{b}} a_{0}=2 d(100) / \sqrt{ } 3$, hexagonal lattice parameter calculated from XRD, estimated error $4 \AA$.

${ }^{\mathrm{c}}$ Calculated by $a_{0}$ - pore size.

${ }^{\mathrm{d}}$ Total pore volume at $P / P_{0}=0.980$.

${ }^{\mathrm{e}}$ Micropore volume determined using the $t$-plot method.

${ }^{\mathrm{f}}$ Pore size from desorption branch applying the BJH pore analysis.

${ }^{\mathrm{g}}$ Derived from the BET equation of the nitrogen adsorption isotherms.

Finally, the diffuse reflectance UV-visible spectra of all catalysts were recorded (Fig. S4 and S5). The spectra of the pure HPA showed two bands at ca. 250 and $360 \mathrm{~nm}$. attributed to octahedral $\left(\mathrm{O}_{\mathrm{h}}\right)$ tungsten species in accord with literature data $[33,34]$. Both encapsulated and impregnated catalysts displayed quite the same patterns with two bands at ca. 200 and $265 \mathrm{~nm}$ which can be ascribed to the charge transfer between oxygen and tungsten. In particular, the well-defined maximum at $265 \mathrm{~nm}$ could be attributed to an $\mathrm{O}^{2-} \rightarrow \mathrm{W}^{6+}$ intraframework $\left(\mathrm{W}_{12} \mathrm{O}_{36}\right)$ charge transfer in the highly dispersed Keggin units. All HPA supported catalysts showed shifted signals with regards to pure HPA indicating a change in the symmetry, the interactions with the support decreasing the tetrahedral symmetry of the Keggin units [33, 34].

\subsection{Study of the Texture of the Catalysts}

The structure of all materials was analyzed by XRD measurements. Small-angle XRD patterns allowed for the identification of the mesostructure and long-range ordering of the silica framework, while wide-angle XRD patterns gave information on the presence or absence of HPA crystallites in the solid and thus on the dispersion of the active phase. The low-angle XRD patterns (Fig. S6 and S7) showed the three well-resolved peaks, indexed as (100), (110) and (200) reflections, characteristic of the hexagonal ordered mesostructure of SBA-15 [35]. These peaks are present for all hybrid materials even for the encapsulated ones, which confirm that adequate SBA-15 mesostructuration was obtained through the sol-gel encapsulation method. The wide-angle XRD patterns (also displayed in Fig. S6 and S7) did not show any peak in the $10-70^{\circ} 2 \theta$ region, suggesting that there are no HPA crystallites in the materials whatever the preparation method used.
The $\mathrm{N}_{2}$ adsorption-desorption isotherms of all materials are shown in Figures S8 and S9 and, as expected, are characteristic of mesoporous materials (type IV isotherms). The physical and textural parameters deduced from these isotherms and from the X-ray diffraction patterns are listed in Table 1. All samples have quite the same $a_{0}$ parameter and the same wall thickness if the measurement errors are taken into account. The main differences stem from the BET surface area and the porous volume. As the tungsten content in the samples is ca. $25 \mathrm{wt} \%$, the HPA loading can be estimated as ca. $33 \mathrm{wt} \%$. The value signifies that one gram of catalyst contains only $0.67 \mathrm{~g}$ of SBA- 15 resulting in a surface area of $0.67 \times 834=560 \mathrm{~m}^{2}$ and a pore volume of $1.10 \times 0.67=0.74 \mathrm{~cm}^{3}$. The experimental values for both encapsulated and impregnated materials are always lower indicating that these solids are slightly less mesostructured than the starting SBA-15 and/or that some pore blocking might occur. Another parameter which can give informative indications on the the adsorbant-surface interaction and consequently on the surface philicity properties is the $C$ constant in the BET equation. As shown in Table 1, the two HPW derived catalysts and the HSiW/SBA-15 solid exhibit higher $C_{B E T}$ values than pure SBA-15 while HSiW@SBA-15 has quite the same surface behavior than plain SBA-15. An increase of $C_{B E T}$ can be related to an increase of the strength of the interaction between sorbed nitrogen molecules and the solid and therefore to an increase of the surface polarity. For pure SBA-15 and HSiW@SBA-15, nitrogen interacts principally with the silica surface while for the three other catalysts it also interacts with HPA species suggesting that HPA accessibility in HSiW@SBA-15 material is much lower than for the other hybrids.

Taken together, the results suggest that, whether impregnated or encapsulated, the HPA have mostly retained their 
primary Keggin structure in the final hybrid materials as evidenced by FT-IR, DR UV-Vis and ${ }^{31} \mathrm{P}$ NMR (for HPW derived materials). The encapsulated catalysts appeared to be less thermally stable than their impregnated counterparts. This is perhaps due to the perturbation caused by the presence of a very significant amount (33 wt $\%$ ) of HPA as part of the silica framework, which is relatively unperturbed in the case of impregnated materials. In addition, the accessibility to active sites in both encapsulated hybrid materials appears to be quite different, with the HPA being probably held more deeply in the interior of the walls in the case of HSiW@SBA-15.

\subsection{Catalytic Experiments}

$n$-Hexane isomerization was chosen as a model reaction as it requires highly acidic sites to proceed and several studies had shown the good catalytic performance of supported HPA in this reaction [36-40]. All experiments were performed with a dynamic system during $12 \mathrm{~h}$ in order to study the deactivation of the catalyst. The four catalysts, which had quite the same tungsten loading, (Tab. 1), were studied in the following conditions: $1 \mathrm{~g}$ of catalyst, reaction temperature $200^{\circ} \mathrm{C}$, atmospheric pressure, flow rate $5 \mathrm{~mL} / \mathrm{min}$ argon and $n$-hexane vapor pressure at $25^{\circ} \mathrm{C}$.

Figure 5 shows the variation of the conversion as a function of time for the four catalysts. It can be clearly seen that the HSiW@SBA-15 catalyst has a behavior completely different from that of the three other systems achieving a steady conversion of ca. $3 \%$ while an initial conversion of $20-25 \%$ was reached with the other catalysts. The HPW/SBA-15 and HSiW/SBA-15 catalysts give quite the same results (same initial activity and same deactivation rate) while the HPW@SBA-15 system displays a slightly higher deactivation rate. A blank test with SBA-15 did not show any conversion (Tab. 2), the small amounts of 3-methylpentane (3MP) and 2,2-dimethylbutane (2.2DMB) corresponding to impurities in the $n$-hexane used for the study.

For all catalysts, the selectivity towards isomerization increases with time on stream (Tab. 2) while the conversion decreases. This phenomenon can be explained by mechanistic considerations. At the first stages of the reaction, the number of active sites is high, allowing for the formation of an alkene via an initial carbocation formation and its subsequent reaction with another carbocation. This bimolecular mechanism is responsible for cracking and thus of the loss of selectivity. When the reaction time increases, the catalyst deactivates leading to a decrease of the amount of active sites, and so of carbocations, resulting in a lower probability for the bimolecular reaction to occur. Plotting the selectivity to isomerization versus the conversion clearly shows that the HPW and HSiW systems have a different behavior,



Figure 5

$n$-hexane conversion as a function of time for the four catalysts.

the silicotungstic acid leading to more selective catalysts at the same conversion (Fig. 6). These results are quite similar to those reported previously $[25,41]$.

The variation of the amounts of the four branched $\mathrm{C}_{6}$ isomers can also be rationalized by plotting their relative proportion (and not the selectivity as depicted in Tab. 2) as a function of the conversion (Fig. S12). Quite the same results are obtained for the three systems (HSiW@SBA-15 is not taken into account as the global conversion is too low). The monobranched products correspond to more than $80 \%$ of the branched isomers (2-methylpentane (2MP) being the major product), 2,3-dimethylbutane (2.3DMB) corresponds to ca. $15 \%$ and $2.2 \mathrm{DMB}$ is minor (ca. $5 \%$ ). These data are far away from the thermodynamic equilibrium (which corresponds to a $n$-hexane conversion of $86 \%$ with the following relative proportions of the four branched isomers: $2 \mathrm{MP} 36 \%$, $3 \mathrm{MP} 23 \%$, 2.2DMB 30\% and 2.3DMB 11\% [42]).

\subsection{Study of the Acidity of the Catalysts by Adsorption- Desorption of Ammonia}

Ammonia is often used as a probe molecule for the determination of the acidity of the solids, for example by studying its adsorption by microcalorimetry or its desorption from a catalyst previously saturated with it (TPD) [43-45]. We used these two methods in order to compare the acidity of the impregnated and encapsulated catalysts as the catalytic reactivity had shown a difference in the behavior of the HSiW@SBA-15 system compared to the three other ones.

Blank experiments of $\mathrm{NH}_{3}$-TPD were first carried out on bulk $\mathrm{H}_{3} \mathrm{PW}_{12} \mathrm{O}_{40}$ and pure SBA-15. The HPA gave a single sharp peak at ca. $650^{\circ} \mathrm{C}$ (Fig. S13) which corresponds to the decomposition of the ammonium salt of the polyoxometalate, 
TABLE 2

Conversions and selectivities at 0 and $12 \mathrm{~h}$ for $n$-hexane isomerization

\begin{tabular}{|c|c|c|c|c|c|c|c|}
\hline \multicolumn{3}{|c|}{ Catalysts } & \multirow[t]{2}{*}{ SBA-15 } & \multirow[t]{2}{*}{ HPW/SBA-15 } & \multirow[t]{2}{*}{ HPW@SBA-15 } & \multirow[t]{2}{*}{ HSiW/SBA-15 } & \multirow[t]{2}{*}{ HSiW@SBA-15 } \\
\hline \multicolumn{2}{|c|}{ Parameters } & Time (h) & & & & & \\
\hline \multirow{2}{*}{\multicolumn{2}{|c|}{ Global Conv. (\%) }} & 0 & 0.83 & 22.5 & 20.1 & 20.7 & 3.0 \\
\hline & & 12 & 0.84 & 7.8 & 6.2 & 7.5 & 1.2 \\
\hline \multirow[t]{14}{*}{ Selectivity (\%) } & \multirow[t]{2}{*}{$3 \mathrm{MP}$} & 0 & 23.0 & 20.6 & 22.5 & 24.3 & 24.1 \\
\hline & & 12 & 22.2 & 24.5 & 23.5 & 26.7 & 21.5 \\
\hline & \multirow[t]{2}{*}{$2 \mathrm{MP}$} & 0 & 0 & 33.9 & 38.0 & 41.3 & 38.8 \\
\hline & & 12 & 0 & 44.3 & 43.8 & 48.4 & 24.1 \\
\hline & \multirow[t]{2}{*}{$2.3 \mathrm{DMB}$} & 0 & 0 & 9.5 & 10.3 & 10.2 & 11.1 \\
\hline & & 12 & 0 & 12.4 & 11.3 & 12.7 & 7.6 \\
\hline & \multirow[t]{2}{*}{ 2.2DMB } & 0 & 77.0 & 0.3 & 0.4 & 2.4 & 20.3 \\
\hline & & 12 & 77.8 & 3.0 & 5.1 & 1.9 & 43.5 \\
\hline & \multirow[t]{2}{*}{$\mathrm{C}_{5}$} & 0 & 0 & 10.6 & 9.1 & 7.3 & 0 \\
\hline & & 12 & 0 & 5.1 & 5.4 & 4.6 & 0 \\
\hline & \multirow[t]{2}{*}{$\mathrm{C}_{4}$} & 0 & 0 & 17.4 & 13.7 & 10.7 & 3.7 \\
\hline & & 12 & 0 & 7.1 & 7.8 & 3.9 & 2.4 \\
\hline & \multirow[t]{2}{*}{$\mathrm{C}_{3}$} & 0 & 0 & 7.7 & 6.0 & 3.8 & 2.0 \\
\hline & & 12 & 0 & 3.6 & 3.1 & 1.8 & 0.9 \\
\hline \multirow{2}{*}{\multicolumn{2}{|c|}{ Selectivity $\mathrm{C}_{6}(\%)$}} & 0 & 100 & 64.3 & 71.2 & 78.2 & 94.3 \\
\hline & & 12 & 100 & 84.2 & 83.7 & 89.7 & 96.7 \\
\hline
\end{tabular}

Reaction conditions: $1 \mathrm{bar}, 200^{\circ} \mathrm{C}, 5 \mathrm{~mL} \cdot \mathrm{min}^{-1}$ argon flow, ratio hexane/argon $=0.25,25 \mathrm{wt} \% \mathrm{~W}, 1 \mathrm{~g}$ of catalyst.

$\left(\mathrm{NH}_{4}\right)_{3} \mathrm{PW}_{12} \mathrm{O}_{40}$. As expected, SBA-15 led to a very small amount of desorbed molecules in agreement with its weak-acidic character with respect to HPA (Fig. S14). The four supported and encapsulated HPA led to similar profiles (Fig. S15). The HPW catalysts presented two relatively broad peaks at 200 and $450^{\circ} \mathrm{C}$ and a relatively sharp one, at quite the same position than that observed for bulk $\mathrm{H}_{3} \mathrm{PW}_{12} \mathrm{O}_{40}\left(650^{\circ} \mathrm{C}\right)$ and attributed to the decomposition of its ammonium salt. This attribution was confirmed by recording the $\mathrm{NH}_{3}$-TPD of $\mathrm{H}_{3} \mathrm{PW}_{12} \mathrm{O}_{40} / \mathrm{SiO}_{2}$ (Fig. S16) with quite the same HPA loading. In that case, due to the lower surface area of Aerosil silica compared to SBA-15, the amount of bulk HPA was higher resulting in a stronger peak at ca. $650^{\circ} \mathrm{C}$. As the two broad signals were not observed in the case of the bulk HPA and of pure SBA-15, they are likely related to HPW species in interaction with the silica support. For HSiW catalysts, only two very broad peaks were noticed around 200 and $500^{\circ}$ C. Unlike to HPW catalysts, the sharp signal associated with the ammonium salt of bulk $\mathrm{H}_{4} \mathrm{SiW}_{12} \mathrm{O}_{40}$, expected around $530^{\circ} \mathrm{C}$ (Fig. S13 and reference [46]), was not observed, only a small very broad signal being present at ca. $700^{\circ} \mathrm{C}$ for HSiW@SBA-15. All these results are in agreement with the data reported in the literature [43, 44, 47].

A more quantitative comparison of the data gives $1.5 \mathrm{mmol} \mathrm{NH}_{3}$ desorbed per $\mathrm{g}$ of $\mathrm{H}_{3} \mathrm{PW}_{12} \mathrm{O}_{40}$ for the bulk HPA, $0.3 \mathrm{mmol} \mathrm{NH}_{3}$ desorbed per $\mathrm{g}$ of SBA-15 and around $2 \mathrm{mmol} \mathrm{NH}_{3}$ desorbed per $\mathrm{g}$ for the SBA-15 supported and encapsulated HPA (Tab. S1). As TCD is not a specific detector, all kind of molecules can be detected and, in the present case, not only $\mathrm{NH}_{3}$ but also water issued from the condensation of two surface hydroxyls and $\mathrm{N}_{2}$ formed by decomposition of ammonia and reduction of the polyoxometalate have been taken into account in the measurements [48]. For the pure HPA, the amount evolved corresponds to 4.3 molecules per polyoxometalate, in agreement with $3 \mathrm{NH}_{3}$ and $1.5 \mathrm{H}_{2} \mathrm{O}$ for the loss of constitution water. For pure SBA-15, 


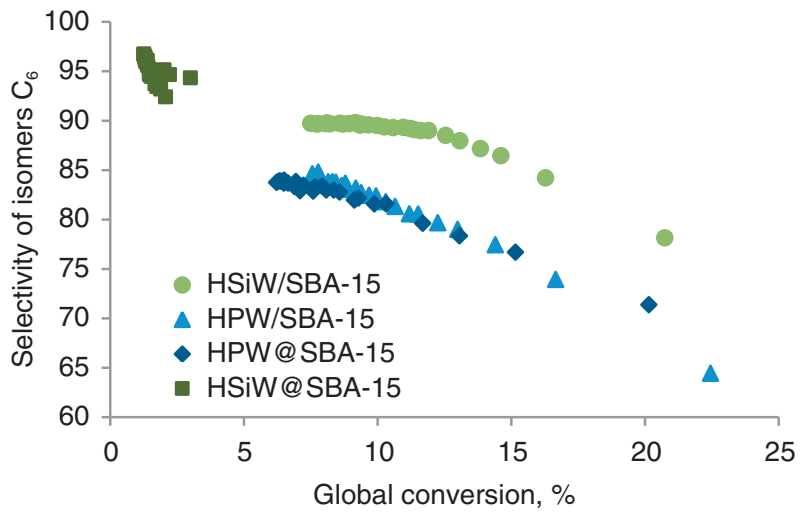

Figure 6

Variation of the selectivity for the $\mathrm{C}_{6}$ branched isomers as a function of the conversion for all catalysts.

the evolved gas is very low $\left(0.3 \mathrm{mmol} . \mathrm{g}^{-1}\right)$ and corresponds probably to the loss of some water by condensation of surface silanol groups, as $\mathrm{Si}-\mathrm{OH}$ are known to be weakly acidic. As a consequence, we can suppose that for the encapsulated and impregnated materials the contribution of the SBA-15 support to the amount evolved is ca. $0.2 \mathrm{mmol}$ (as these samples contain ca. $33 \mathrm{wt} \%$ of polyacid). The remaining $1.8 \mathrm{mmol}$ are due to the polyoxometalate and correspond to the evolution of ca. 1.6 molecules (which are not necessary $\mathrm{NH}_{3}$ ) per Keggin unit. This value is very low compared to that achieved with the pure polyacid and is probably related to the formation of covalent bonds between the polyoxometalate and the support with the concomitant evolution of water during the samples pretreatment at $300^{\circ} \mathrm{C}$ [49]. This method seems therefore inadequate to meaningfully compare the acidity properties of the different hybrids with their catalytic performance. The ammonia TPD was also studied by using a DRIFT/GC-MS apparatus (Fig. S17 to S20). This study confirmed the evolution of water. In addition, the IR spectra recorded after desorption of ammonia at $20^{\circ} \mathrm{C}$ showed a clear difference between the HSiW@SBA-15 solid and the three other catalysts as indicated by the very low intensity of the $v(\mathrm{~N}-\mathrm{H})$ band at ca. $3300 \mathrm{~cm}^{-1}$ (Fig. 7). Since the intensity of this band is related to the amount of sorbed ammonia on the solid and thus to its acidity, ammonia desorption appears, here, to correlate quite well with the catalytic activity trends and could be used for the study of such materials but a special care must be taken with the detection methods.

The adsorption of ammonia by microcalorimetry was also investigated. In that case, only small pulses of ammonia were injected on the sample to prevent any decomposition of the polyoxometalate. The catalysts were pretreated under vacuum at $200^{\circ} \mathrm{C}$ (such treatment was previously shown to

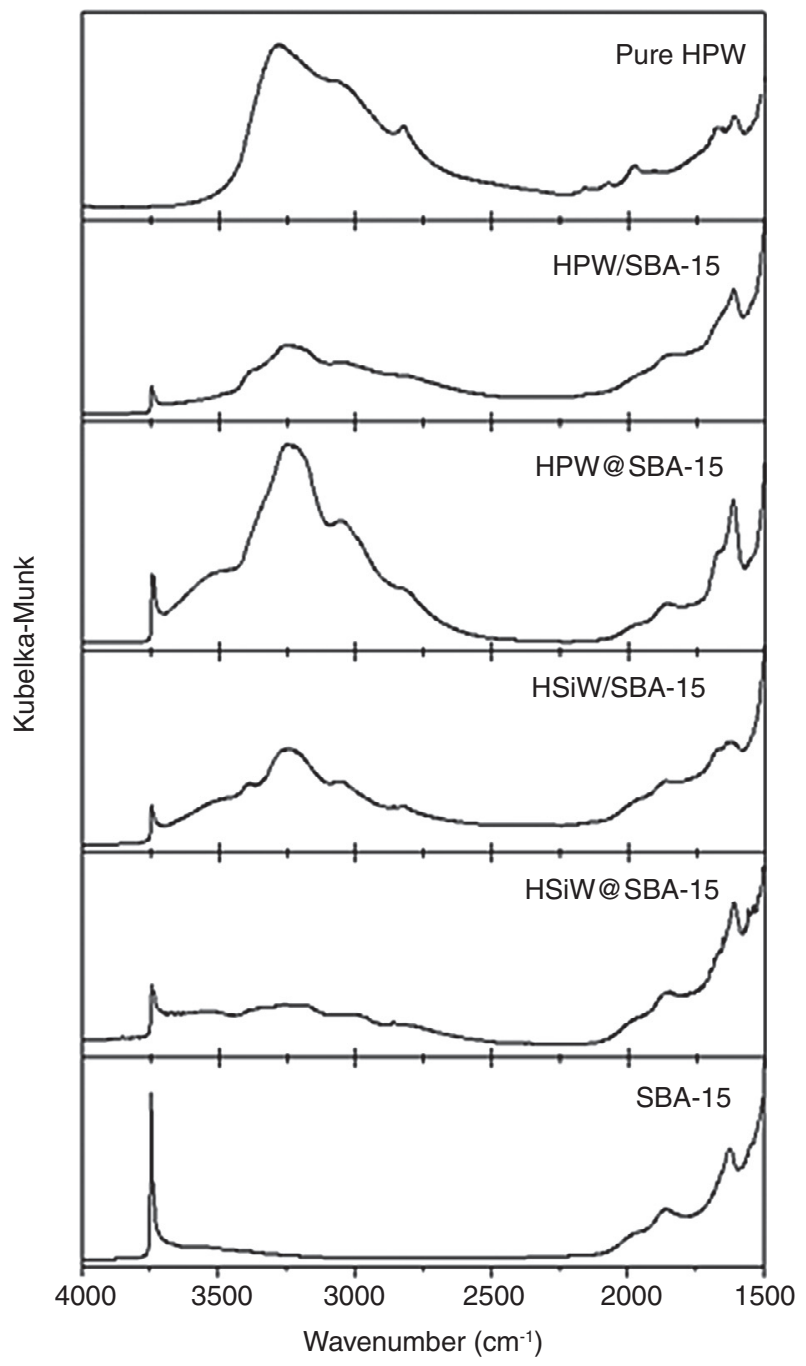

Figure 7

FT-IR spectra of catalysts after $\mathrm{NH}_{3}$ adsorption and desorption at $20^{\circ} \mathrm{C}$.

remove the crystallization water [50]) as the $\mathrm{NH}_{3}$-TPD study had shown that a treatment at $300^{\circ} \mathrm{C}$ resulted in a high amount of covalent bonds between the support and the Keggin unit. The ammonia adsorption was performed at $80^{\circ} \mathrm{C}$, as for classical experiments. Figure 8 shows the differential heats of ammonia as a function of the coverage for the four catalysts. As expected, SBA-15 showed only a very small amount of adsorbed ammonia with differential heats around $80 \mathrm{~kJ} \cdot \mathrm{mol}^{-1}$ (Fig. S21).

Figure S22 shows that for the four solids the adsorption curve can be decomposed in two parts, a rapid one at low pressure and a slow one at higher pressure. A comparison with the curve obtained for pure SBA-15 (Fig. S23) allows us to propose that the slow part is likely due to ammonia 


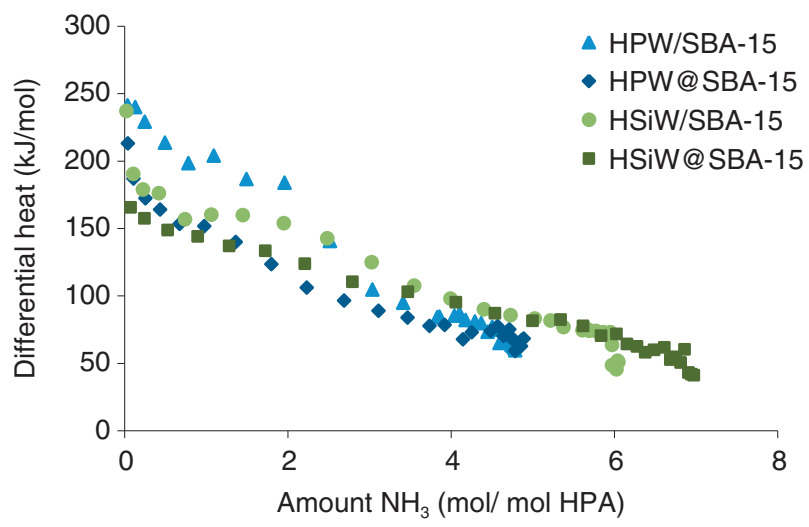

Figure 8

Differential heat of ammonia adsorption as a function of the ammonia coverage.

physisorption on the support. Extrapolation of the first part of the curves gives an adsorption of ca. $3 \mathrm{NH}_{3}$ per Keggin unit for the HPW-based materials and ca. $4 \mathrm{NH}_{3}$ for the HSiW-based ones, in agreement with the molecular formula of the corresponding HPA and the absence of covalent bonds with the SBA-15 support.

Figure 8 shows that the four solids display also quite the same behavior in terms of differential heat of ammonia adsorption with a continuous decrease as a function of the amount adsorbed. This result is in agreement with previous data for $\mathrm{H}_{3} \mathrm{PW}_{12} \mathrm{O}_{40}$ supported on Aerosil silica [51]. In contrast, studies of the adsorption of ammonia on pure HPA had shown the presence of a plateau with a constant differential heat of adsorption [51-53]. These data were interpreted as a measure of the heat of formation of the ammonium salt of the polyoxometalate which is stable until ca. $600^{\circ} \mathrm{C}$. In the present case, Figure 8 shows that HPW/SBA-15 displays higher differential heats of adsorption than the other catalysts with the presence of a small plateau at $200 \mathrm{~kJ} \cdot \mathrm{mol}^{-1}$. The three other solids show quite the same curves even if the HSiW@SBA-15 material has a smaller initial differential heat of adsorption. However, this difference cannot account for the complete inactivity of HSiW@SBA in the isomerization of $n$-hexane. Here also, the results obtained by microcalorimetry do not fit with the catalytic experiments.

\subsection{Study of the Acidity by Adsorption of Pyridine}

Pyridine adsorption is often used to study the acidity of catalysts as it allows differentiating between Lewis and Brønsted acid sites. As for the above studies, the solids were pretreated under vacuum at $200^{\circ} \mathrm{C}$ before adsorption of pyridine at room temperature and desorption at increasing

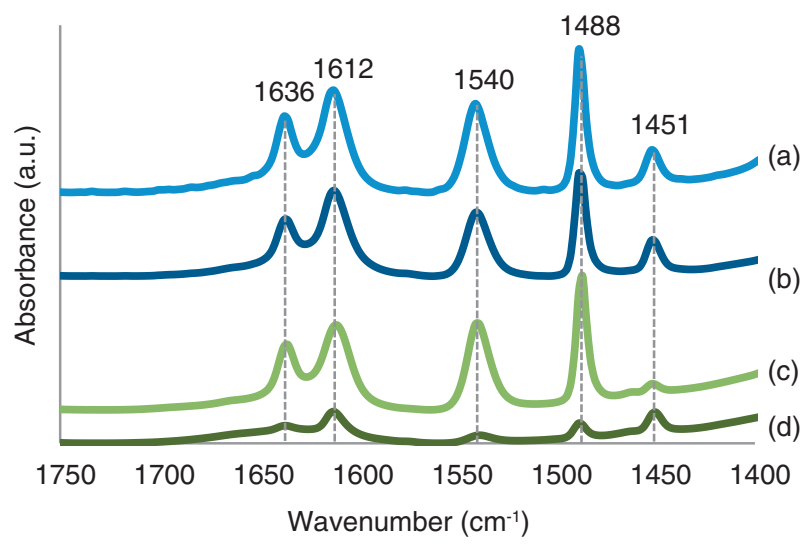

Figure 9

FT-IR spectra of the supported HPA after adsorption of pyridine at room temperature and desorption at $200^{\circ} \mathrm{C}$ under vacuum a) HPW/SBA-15; b) HPW@SBA-15; c) HSiW/SBA-15 and d) HSiW@SBA-15.

temperatures. Figure 9 shows the FT-IR spectra obtained after desorption at $200^{\circ} \mathrm{C}$, which can be considered as representative of the acid sites at the catalysis temperature. The spectra after desorption at lower temperatures are given in the supplementary material, Figures S24 to S27. These spectra were scaled to each other by giving the same height to the harmonic vibrational bands of the support in the $2000-1800 \mathrm{~cm}^{-1}$ range. As a consequence, they can be directly compared. Among all the bands present on the spectra, the most important ones are those at 1540 and ca. $1450 \mathrm{~cm}^{-1}$ which are characteristic of Brønsted and Lewis acid sites respectively $[54,55]$. One can notice that the HSiW@SBA-15 catalyst contains only a very small amount of Brønsted acid sites compared to the three other solids which have quite the same amount of acid sites. In all cases, the amount of Lewis acid sites is very low as demonstrated by the weak intensity of the band at $1450 \mathrm{~cm}^{-1}$. These results are in good agreement with the catalytic data and those obtained by infrared spectroscopy after adsorption/desorption of ammonia.

The difference between microcalorimetry and the other methods (TPD by taking into account only sorbed ammonia and pyridine adsorption) cannot be only due to activation problems as pyridine was adsorbed after treatment at $200^{\circ} \mathrm{C}$, as for the calorimetric study. The main difference is that for TPD and pyridine adsorption the samples were desorbed at room temperature. It must then be supposed that in the case of the HSiW@SBA-15 catalyst the sorbed ammonia molecules can be more easily desorbed at low temperature. This could be related to a more pronounced encapsulation of the HPA within the walls of the SBA-15 framework which is further supported by a $C_{B E T}$ value very close to that of bare SBA- 15 . 


\section{CONCLUSION}

Four HPA-based catalysts were prepared by encapsulation or impregnation of $\mathrm{H}_{3} \mathrm{PW}_{12} \mathrm{O}_{40}$ and $\mathrm{H}_{4} \mathrm{SiW}_{12} \mathrm{O}_{40}$ onto SBA-15 silica. These solids were characterized by various physicochemical methods which showed that, after the catalyst preparation, the Keggin structure of the polyoxometalate had been retained in all cases. DTA and Raman studies confirm that the encapsulated materials were thermally less stable than the impregnated ones.

The HPW/SBA-15, HPW@SBA-15 and HSiW/SBA-15 catalysts performed similarly in the isomerization of $n$-hexane with a good selectivity ( $>80 \%)$. On the other hand, HSiW@SBA-15 was slightly active with a conversion of only $3 \%$ although more selective. To get deeper insight into the discrepancy in catalytic behavior observed with HSiW@SBA-15, the acid properties of the four solids were studied by adsorption and/or desorption of ammonia (using microcalorimetry, TPD and DRIFT/GC-MS desorption) and pyridine adsorption/desorption monitored by FT-IR. Only pyridine adsorption/desorption and DRIFT/GC-MS of ammonia desorption led to meaningful results in accord with catalysis data. A possible explanation to account for the inactivity of HSiW@SBA-15 is that the silicotungstate anions are located more deeply within the silica framework resulting in less acidic materials. The polyoxometalate could then be accessible to small molecules such as ammonia but it could not be reached by larger molecules such as pyridine or $n$-hexane.

\section{ACKNOWLEDGMENTS}

The authors wish to acknowledge Dr. Jean-Marc Millet from IRCE Lyon for performing the ammonia TPD experiments.

\section{REFERENCES}

1 Pope M.T. (1983) Heteropoly and Isopoly Oxometalates, Springer Verlag.

2 Kozhevnikov I.V. (1998) Catalysis by Heteropoly Acids and Multicomponent Polyoxometalates in Liquid-Phase Reactions, Chem. Rev. 98, 171-198.

3 Mizuno N., Misono M. (1998) Heterogeneous Catalysis, Chem. Rev. 98, 199-217.

4 Timofeeva M.N. (2003) Acid Catalysis by Heteropolyacids, Appl. Catal. A: Gen. 256, 19-35.

5 Newman A.D., Lee A.F., Wilson K., Young N.A. (2005) On the Active Site in $\mathrm{H}_{3} \mathrm{PW}_{12} \mathrm{O}_{40} / \mathrm{SiO}_{2}$ Catalysts for Fine Chemical Synthesis, Catal. Lett. 102, 45-50.

6 Okuhara T., Mizuno N., Misono M. (2001) Catalysis by Heteropoly Compounds - Recent Developments, Appl. Catal. A: Gen. 222, 63-77.
7 Zhao D., Feng J., Huo Q., Melosh N., Fredrickson G.H., Chmelka B.F., Stucky G.D. (1998) Triblock Copolymer Syntheses of Mesoporous Silica with Periodic 50 to 300 Angstrom Pores, Science 279, 548-552.

8 Zhao D., Huo Q., Feng J., Chmelka B.F., Stucky G.D. (1998) Nonionic Triblock and Star Diblock Copolymer and Oligomeric Surfactant Syntheses of Highly Ordered, Hydrothermally Stable, Mesoporous Silica Structures, J. Am. Chem. Soc. 120, 6024-6036.

9 Zhao D., Sun J., Li Q., Stucky G.D. (2000) Morphological Control of Highly Ordered Mesoporous Silica SBA-15, Chem. Mater. 12, 275-279.

10 Dufaud V., Lefebvre F. (2010) Inorganic Hybrid Materials with Encapsulated Polyoxometalates, Materials 3, 682-703.

11 Falco M.G., Canavese S.A., Comelli R.A., Fígoli N.S. (2000) Influence of Pt Concentration on Tungsten Oxide-Promoted Zirconia during $n$-Hexane Isomerization, Appl. Catal. A: Gen. 201, 37-43.

12 Gagea B.C., Lorgouilloux Y., Altintas Y., Jacobs P.A., Martens J.A. (2009) Bifunctional Conversion of $n$-Decane over HPW Heteropoly Acid Incorporated into SBA-15 during Synthesis, J. Catal. 265, 99-108.

13 Kamiya Y., Okuhara T., Misono M., Miyaji A., Tsuji K., Nakajo T. (2008) Catalytic Chemistry of Supported Heteropolyacids and their Applications as Solid Acids to Industrial Processes, Catal. Surv. Asia 12, 101-113.

14 Yang W., Billy J., Ben Taârit Y., Védrine J.C., Essayem N. (2002) $\mathrm{H}_{3} \mathrm{PW}_{12} \mathrm{O}_{40}$ Supported on Cs Modified Mesoporous Silica: Catalytic Activity in $n$-Butane Isomerization and in situ FTIR Study Comparison with Microporous $\mathrm{Cs}_{x} \mathrm{H}_{3-x} \mathrm{PW}_{12} \mathrm{O}_{40}$, Catal.Today 73, 153-165.

15 Essayem N., Ben Taârit Y., Feche C., Gayraud P.Y., Sapaly G., Naccache C. (2003) Comparative Study of $n$-Pentane Isomerization over Solid Acid Catalysts, Heteropolyacid, Sulfated Zirconia, and Mordenite: Dependence on Hydrogen and Platinum Addition, J. Catal. 219, 97-106.

16 Sousa B.V., Brito K.D., Alves J.J.N., Rodrigues M.G.F., Yoshioka C.M.N., Cardoso D. (2011) $n$-Hexane Isomerization on Pt/HMOR: Effect of Platinum Content, React. Kinet. Mech. Catal. 102, 473-485.

17 Ono Y. (2003) A Survey of the Mechanism in Catalytic Isomerization of Alkanes, Catal. Today 81, 3-16.

18 Bernard P.M., Primet M. (1990) Influence of Hydrogen Chloride Addition on the Catalytic Isomerization Activity of Chlorinated Alumina and Chlorinated Platinum-Alumina Solids, J. Chem. Soc., Faraday Trans. 86, 567-570.

19 Otten M.M., Clayton M.J., Lamb H.H. (1994) PlatinumMordenite Catalysts for $n$-Hexane Isomerization: Characterization by X-Ray Absorption Spectroscopy and Chemical Probes, J. Catal. 149, 211-222.

20 Miyaji A., Echizen T., Li L., Suzuki T., Yoshinaga Y., Okuhara T. (2002) Selectivity and Mechanism for Skeletal Isomerization of Alkanes over Typical Solid Acids and their Pt-Promoted Catalysts, Catal. Today 74, 291-297.

21 Modhera B.K., Chakraborty M., Bajaj H.C., Parikh P.A. (2011) Influences of Mesoporosity Generation in ZSM-5 and Zeolite Beta on Catalytic Performance During $n$-Hexane Isomerization, Catal. Lett. 141, 1182-1190.

22 Aboul-Gheit A.K., Abdel-Hamid S.M., El-Desouki D.S. (2010) Hydroisomerization of $n$-Hexane using Unloaded and lowPlatinum-Loaded H-ZSM-5 and H-MOR Catalysts, Petroleum Sci. Technol. 28, 582-593. 
23 Guisnet M., Costa L., Ribeiro F.R. (2009) Prevention of Zeolite Deactivation by Coking, J. Mol. Catal. A: Chem. 305, 69-83.

24 Weitkampf J. (1982) Isomerization of Long-Chain n-Alkanes on a Pt/CaY Zeolite Catalyst, Ind. Eng. Chem. Prod. Res. Dev. 21, 550-558.

25 Pinto T., Dufaud V., Lefebvre F. (2014) Isomerization of $n$-Hexane on Heteropolyacids Supported on SBA-15. 1. Monofunctional Impregnated Catalysts, Appl. Catal. A: Gen. 483, 103-109.

26 Dufaud V., Lefebvre F., Niccolai G.P., Aouine M. (2009) New Insights into the Encapsulation and Stabilization of Heteropolyacids inside the Pore Walls of Mesostructured Silica Materials, J. Mater. Chem. 19, 1142-1150.

27 Ghanbari-Siahkali A., Philippou A., Dwyer J., Anderson M.W. (2000) The Acidity and Catalytic Activity of Heteropoly Acid on MCM-41 Investigated by MAS NMR, FTIR and Catalytic Tests, Appl. Catal. A: Gen. 192, 57-69.

28 Okuhara T., Nishimura T., Watanabe H., Misono M. (1992) Catalysis by Heteropoly Compounds. XXI. Insoluble Heteropoly Compounds as Highly Active Catalysts for Liquid-Phase Reactions, J. Mol. Catal. 74, 247-256.

29 Carriazo D., Domingo C., Martín C., Rives V. (2008) PMo or PW Heteropoly Acids Supported on MCM-41 Silica Nanoparticles: Characterisation and FT-IR Study of the Adsorption of 2-Butanol, J. Solid State Chem. 181, 2046-2057.

30 Legagneux N., Basset J.M., Thomas A., Lefebvre F., Goguet A., Sa J., Hardacre C. (2009) Characterization of SilicaSupported Dodecatungstic Heteropolyacids as a Function of their Dehydroxylation Temperature, Dalton Trans., 2235-2240.

31 Rocchiccioli-Deltcheff C., Thouvenot R., Franck R. (1976) Ir and Raman Spectra of Heteropolyanions with Keggin-Type Structure, $\alpha-\mathrm{XM}_{12} \mathrm{O}_{40}{ }^{n-}[\mathrm{X}=\mathrm{B}(\mathrm{III}), \mathrm{Si}(\mathrm{IV}), \mathrm{Ge}(\mathrm{IV}), \mathrm{P}(\mathrm{V}), \mathrm{As}(\mathrm{V}) ; \mathrm{M}=\mathrm{W}$ (VI), Mo(VI)], Spectrochim. Acta Part A 32, 587-597.

32 Lu D.Y., Chen J., Chen H.J., Gong L., Deng S.Z., Xu N.S., Liu Y.L. (2007) Raman Study of Thermochromic Phase Transition in Tungsten Trioxide Nanowires, Appl. Phys. Lett. 90, 041919/1-041919/3.

33 Thielemann J.P., Ressler T., Walter A., Tzolova-Müller G., Hess C. (2011) Structure of Molybdenum Oxide Supported on Silica SBA-15 Studied by Raman, UV-Vis and X-Ray Absorption Spectroscopy, Appl. Catal. A: Gen. 399, 28-34.

34 Lizama L., Klimova T. (2008) Highly Active Deep HDS Catalysts Prepared Using Mo and W Heteropolyacids Supported on SBA-15, Appl. Catal. B: Env. 82, 139-150.

35 Lefebvre F. (1992) Phosphorus-31 MAS NMR Study of $\mathrm{H}_{3} \mathrm{PW}_{12} \mathrm{O}_{40}$ Supported on Silica: Formation of $\left(\equiv \mathrm{SiOH}_{2}^{+}\right)\left(\mathrm{H}_{2} \mathrm{PW}_{12} \mathrm{O}_{40}{ }^{-}\right)$, J. Chem. Soc., Chem. Commun., 756-757.

36 Essayem N., Ben Taârit Y., Gayraud P.Y., Sapaly G., Naccache C. (2001) Heteropolyacid Catalysts for Hydroisomerization of n-Hexane: Effects of Alkali Salt Modification, J. Catal. 204, 157-162.

37 Gherib A., Aouissi A., Rives A., Fournier M., Hubaut R. (2007) Isomerization of $n$-Hexane over Silica-Supported Hetero Polyoxometallates Promoted by Pt-Ce Oxides, Chin. J. Catal. 28, 1041-1046.

38 Hubaut R., Ben Tayeb B.O., Rives A., Fournier M. (2004) Mechanical Mixtures of $\mathrm{PdCeO}$ and $\mathrm{HPA} / \mathrm{SiO}_{2}$ : Structure and Reactivity for $n$-Hexane Isomerization, Solid State Ionics 172, 85-87.
39 Ivanov A.V., Vasina T.V., Nissenbaum V.D., Kustov L.M., Timofeeva M.N., Houzvicka J.I. (2004) Isomerization of $n$-Hexane on the Pt-promoted Keggin and Dawson Tungstophosphoric Heteropoly Acids Supported on Zirconia, Appl. Catal. A: Gen. 259, 65-72.

40 Macht J., Carr R.T., Iglesia E. (2009) Consequences of Acid Strength for Isomerization and Elimination Catalysis on Solid Acids, J. Am. Chem. Soc. 131, 6554-6565.

41 Grinenval E., Garron A., Lefebvre F. (2013) n-Butane Isomerization over Silica-Supported Heteropolyacids: Study of Some Parameters, J. Catal. 2013, ID 828962, 8 pages.

42 Alberty R.A., Gehrig C.A. (1984) Standard Chemical Thermodynamic Properties of Alkane Isomer Groups, J. Phys. Chem. Ref. Data 13, 1173-1197.

43 Kamiya Y., Okuhara T., Misono M., Miyaji A., Tsuji K., Nakajo T. (2008) Catalytic Chemistry of Supported Heteropolyacids and Their Applications as Solid Acids to Industrial Processes, Catal. Surveys Asia 12, 101-113.

44 Zhang J., Kanno M., Wang Y., Nishii H., Miura Y.K., Kamiya Y. (2011) Changes in Surface Acidity of Silica-Supported Dodecatungstosilicic Acid in Relation to the Loading Amount, J. Phys. Chem. C 115, 14762-14769.

45 Zhang J., Kanno M., Zhang J., Ohnishi R., Toriyabe K., Matsuhashi H., Kamiya Y. (2010) Preferential Oligomerization of Isobutene in a Mixture of Isobutene and 1-Butene over Sodium-Modified 12-Tungstosilicic Acid Supported on Silica, J. Mol. Catal. A: Chem. 326, 107-112.

46 Miyaji A., Echizen T., Nagata K., Yoshinaga Y., Okuhara T. (2003) Selective Hydroisomerization of $n$-Pentane to Isopentane over Highly Dispersed $\mathrm{Pd}-\mathrm{H}_{4} \mathrm{SiW}_{12} \mathrm{O}_{40} / \mathrm{SiO}_{2}, J$. Mol. Catal. A: Chem. 201, 145-153.

47 Xu Y., Zhang X., Li H., Qi Y., Lu G., Li S. (2009) Promotion Effect of Lanthanum Addition on the Catalytic Activity of Zirconia Supported Platinum and Tungstophosphoric Acid Catalyst for $n$-Pentane Isomerization, Appl. Surf. Sci. 255, 6504-6507.

48 Essayem N., Frety R., Coudurier G., Védrine J.C. (1997) Ammonia Adsorption-Desorption over the Strong Solid Acid Catalyst $\mathrm{H}_{3} \mathrm{PW}_{12} \mathrm{O}_{40}$ and its $\mathrm{Cs}^{+}$and $\mathrm{NH}_{4}{ }^{+}$Salts. Comparison with Sulfated Zirconia, J. Chem. Soc., Faraday Trans. 93, 3243-3248.

49 Grinenval E., Rozanska X., Baudouin A., Berrier E., Delbecq F., Sautet P., Basset J.M., Lefebvre F. (2010) Controlled Interactions between Anhydrous Keggin-Type Heteropolyacids and Silica Support: Preparation and Characterization of WellDefined Silica-Supported Polyoxometalate Species, J. Phys. Chem. C 114, 19024-19034.

50 Essayem N., Tong Y.Y., Jobic H., Védrine J.C. (2000) Characterization of Protonic Sites in $\mathrm{H}_{3} \mathrm{PW}_{12} \mathrm{O}_{40}$ and $\mathrm{Cs}_{1.9} \mathrm{H}_{1.1} \mathrm{PW}_{12} \mathrm{O}_{40}$ : a Solid-State ${ }^{1} \mathrm{H},{ }^{2} \mathrm{H},{ }^{31} \mathrm{P}$ MAS-NMR and Inelastic Neutron Scattering Study on Samples Prepared under Standard Reaction Conditions, Appl. Catal. A: Gen. 194-195, $109-122$

51 Hamad B., Lopes de Souza R.O., Sapaly G., Carneiro Rocha M.G., Pries de Oliveira P.G., Gonzalez W.A., Andrade Sales E., Essayem N. (2008) Transesterification of Rapeseed Oil with Ethanol over Heterogeneous Heteropolyacids, Catal. Commun. 10, 92-97.

52 Jozefowicz L.C., Karge H.G., Vasilyeva E., Moffat J.B. (1993) A Microcalorimetric Investigation of Heteropolyacids, Microp. Mater. 1, 313-322. 
53 Lefebvre F., Liu-Cai F.X., Auroux A. (1994) Microcalorimetric Study of the Acidity of Tungstic Heteropolyanions, J. Mater. Chem. 4, 125-131.

54 Zaki M.I., Hasan M.A., Al-Sagheer F.A., Pasupulety L. (2001) In situ FTIR Spectra of Pyridine Adsorbed on $\mathrm{SiO}_{2}-\mathrm{Al}_{2} \mathrm{O}_{3}$, $\mathrm{TiO}_{2}, \mathrm{ZrO}_{2}$ and $\mathrm{CeO}_{2}$ : General Considerations for the Identification of Acid Sites on Surfaces of Finely Divided Metal Oxides, Colloids Surf. A 190, 261-274.

55 Zaki M.I., Mekhemer G.A.H., Fouad N.E., Rabee A.I.M. (2014) Structure-Acidity Correlation of Supported Tungsten
(VI) -Oxo-Species: FT-IR and TPD Studies of Adsorbed Pyridine and Catalytic Decomposition of 2-Propanol, Appl. Surf. Sci. 308, 380-387.

Manuscript submitted in July 2015

Manuscript accepted in March 2015

Published online in April 2016

Cite this article as: T. Pinto, K. Szeto, N. Oueslati, N. Essayem, V. Dufaud and F. Lefebvre (2016). Comparison of the Acidity of Heteropolyacids Encapsulated in or Impregnated on SBA-15, Oil Gas Sci. Technol 71, 25. 